\title{
Stability of aortic annulus enlargement during aortic valve replacement using a bovine pericardial patch: An 18-year clinical, echocardiographic, and angio-computed tomographic follow-up
}

\author{
Michele Celiento, MD, ${ }^{\mathrm{a}}$ Matteo Saccocci, MD, ${ }^{\mathrm{a}}$ Andrea De Martino, MD, ${ }^{\mathrm{a}}$ Carmela Nardi, MD, \\ Lorenzo Faggioni, MD, ${ }^{\mathrm{c}}$ Aldo D. Milano, MD, $\mathrm{PhD},{ }^{\mathrm{d}}$ and Uberto Bortolotti, $\mathrm{MD}^{\mathrm{a}}$
}

\begin{abstract}
Objective: Enlargement of the aortic annulus may be required during aortic valve replacement to avoid patientprosthesis mismatch. We reviewed patients with enlargement of the aortic annulus with the aim of assessing the stability of the procedure by means of echocardiographic and angio-computed tomography studies.

Methods: A series of 53 consecutive patients underwent aortic valve replacement and enlargement of the aortic annulus from 1994 to 2012. The mean age was $68 \pm 11$ years (range, 29-84 years), and 85\% (45 patients) were female. The predominant valvular lesion was aortic stenosis. The mean logistic European System for Cardiac Operative Risk Evaluation was $11.2 \pm 13.0$. Enlargement of the aortic annulus was performed by extending the aortotomy incision to separate the commissure between the left and noncoronary sinuses into the anterior mitral leaflet and closing the resulting defect with an adequately tailored patch of bovine pericardium.
\end{abstract}

Results: Hospital mortality was $2 \%$, with 20 late deaths mostly due to noncardiac causes. At a maximum followup of 18 years (mean, $8.9 \pm 5.0$ years), actuarial survival is $37 \% \pm 9 \%$. No cases of severe patient-prosthesis mismatch were observed, and only 2 patients had moderate patient-prosthesis mismatch. At discharge, the mean aortic root diameter was $30.0 \pm 2.3 \mathrm{~mm}$ and the mean diameter at the sinotubular junction was $31.5 \pm 5.0 \mathrm{~mm}$. At followup, the mean aortic root diameter was $31.0 \pm 3.4 \mathrm{~mm}$ and the mean diameter at the sinotubular junction was $31.7 \pm 4.5 \mathrm{~mm}$ ( $P=$ not significant) with no cases of late aneurysm formation on angio-computed tomography.

Conclusions: Enlargement of the aortic annulus is a safe and effective procedure and should be indicated in patients with a small aortic annulus; particularly, it should be considered to prevent patient-prosthesis mismatch and its potential deleterious long-term effects. (J Thorac Cardiovasc Surg 2014;147:977-83)

Enlargement of the aortic annulus (EAA) may be required during aortic valve replacement (AVR) to insert a prosthesis of adequate size and avoid potential patient-prosthesis mismatch (PPM). ${ }^{1}$ Although techniques to perform EAA were introduced more than 4 decades ago, ${ }^{2-5}$ little is known about the long-term results with particular regard to the late changes in aortic root dimensions and whether pericardial patches, when used in such procedures, may be prone to aneurysmal dilatation over time. We review our experience with a series of patients undergoing EAA at the time of AVR using patches of bovine pericardium and verify the long-term follow-up stability of this procedure by means of echocardiographic and angio-computed tomography (ACT) studies.

\footnotetext{
From the Divisions of Cardiac Surgery, ${ }^{\mathrm{a}}$ Cardiology, ${ }^{\mathrm{b}}$ and Radiology, ${ }^{\mathrm{c}}$ University Hospital, Pisa, Italy; and the Division of Cardiac Surgery, ${ }^{\mathrm{d}}$ University of Verona, Verona, Italy.

Disclosures: Authors have nothing to disclose with regard to commercial support. Received for publication Oct 18, 2012; revisions received Feb 14, 2013; accepted for publication Feb 28, 2013; available ahead of print March 29, 2013.

Address for reprints: Uberto Bortolotti, MD, Sezione Autonoma di Cardiochirurgia Universitaria, Università di Pisa, Via Paradisa, 2, 56124 Pisa, Italy (E-mail: uberto.bortolotti@med.unipi.it).

$0022-5223 / \$ 36.00$

Copyright (c) 2014 by The American Association for Thoracic Surgery http://dx.doi.org/10.1016/j.jtcvs.2013.02.074
}

\section{MATERIALS AND METHODS}

From August 1994 to December 2009, 2248 patients underwent AVR; concomitant EAA was performed in $53(2.4 \%)$ of these patients, and they form the basis of this report, representing the entire subset of patients having EAA during this time interval. This retrospective study was approved by the ethics committee of University Hospital of Pisa, Italy. All patients were informed of the nature of the study, which included clinical, echocardiographic, and ACT examinations, and gave their consent to participate, allowing collection and analysis of their clinical and follow-up data.

\section{Surgical Technique}

The technique of aortic annulus enlargement routinely used in University Hospital of Pisa, Italy, has been described ${ }^{6,7}$ and is similar to that proposed by Nunez and colleagues ${ }^{8}$ in 1983 . The operation is performed through a median sternotomy with standard cardiopulmonary bypass and moderate systemic hypothermia, topical cooling, and antegrade cold blood cardioplegia. After aortic crossclamping, a transverse aortotomy is performed and the aortic valve is excised with debridement of the annulus, which is measured with commercially available sizers. In the presence of a diminutive aortic annulus ( $\leq 19 \mathrm{~mm}$ ), EAA was considered indicated on the basis of patient's body surface area (BSA). More recently, avoidance of PPM has been based on the criteria defined by Pibarot and Dumesnil. ${ }^{9}$ For EAA, the aortotomy is carried down through the commissure between the left and noncoronary sinuses into the interleaflet triangle and anterior mitral leaflet. The extension of the incision depends on the patient's anatomy and the surgeon's judgment; however, in any case, opening the roof of the left atrium is carefully avoided. The incision is then closed using a teardrop-shaped patch of pericardium, with a maximal width of approximately $2 \mathrm{~cm}$, sutured with a continuous suture of 4-0 polypropylene starting at the nadir of the incision. In the present series, 


$$
\begin{aligned}
& \text { Abbreviations and Acronyms } \\
& \text { ACT = angio-computed tomography } \\
& \text { AVR = aortic valve replacement } \\
& \text { BSA = body surface area } \\
& \text { EAA }=\text { enlargement of the aortic annulus } \\
& \text { iEOA }=\text { indexed effective orifice area } \\
& \text { LV }=\text { left ventricular } \\
& \text { NYHA }=\text { New York Heart Association } \\
& \text { PPM }=\text { patient-prosthesis mismatch } \\
& \text { STJ }=\text { sinotubular junction }
\end{aligned}
$$

glutaraldehyde-fixed bovine pericardium was used. As a consequence, the aortic annulus is enlarged on the basis of the width of the pericardial patch. Both mechanical and bioprosthetic valves were implanted using multiple sutures of 2-0 Ethibond (Ethicon Ltd, Livingston, Scotland) reinforced by Teflon felts placed in the subannular position. At the level of the pericardial patch, sutures were passed from outside to inside leaving the pledgets externally. After the prosthesis was seated and the sutures were tied, the aortotomy was closed using the pericardial patch, thus obtaining partial enlargement of the aortic root. At the end of the procedure, fibrin glue was applied to the sutures to improve hemostasis. All patients were given subcutaneous calcium heparin or low-weight heparin postoperatively; oral anticoagulants were started on postoperative day 1 or after extubation, and heparin was suspended when a target international normalized ratio of 2 to 3 was reached. Anticoagulants were maintained indefinitely in patients with a mechanical prosthesis and for only 3 months after AVR in those with a bioprosthesis, except in patients with chronic atrial fibrillation or other risk factors for thromboembolic complications. However, since 2006, most patients having a tissue valve for AVR receive only antiplatelet drugs.

\section{Follow-up}

After discharge, all patients were encouraged to refer to our outpatient clinic for periodical evaluations, which were scheduled at 1,3, and 6 months after surgery and on a yearly basis thereafter, to obtain information on their clinical status and on the rate and type of any postoperative complications that were defined using established guidelines. ${ }^{10}$ For patients who were unable to come to the outpatient clinic, information was gathered from phone interviews or by contacting relatives or referring physicians. The last follow-up update was conducted during a 6-month interval ending in September 2012. The mean duration of follow-up, which is $92 \%$ complete, is $8.9 \pm 5.0$ years (range, $0.3-18$ years). Four patients could not be traced. The mean follow-up of late survivors is $10.8 \pm 5$ years (range, $3.5-18$ years).

\section{Echocardiographic Controls}

Because the primary end point of the study, in addition to patient survival and freedom from major valve-related events, was to verify the stability of the repair at long-term follow-up, all long-term survivors underwent a transthoracic 2-dimensional echocardiographic control examination at University Hospital of Pisa, Italy. The goal was to assess late prosthetic performance and overall cardiac function by evaluating mean and peak transprosthetic gradients, effective orifice area, left ventricular (LV) ejection fraction, LV diameters and volumes, and degree of LV hypertrophy by means of the LV septal thickness. Aortic root diameters, taken at the levels of the sinuses of Valsalva and the sinotubular junction (STJ), were compared with those calculated at the time of discharge to exclude any evidence of aortic root dilatation. The occurrence of PPM also was considered and defined as mild when the indexed effective orifice area (iEOA) was 0.85 $\mathrm{cm}^{2} / \mathrm{m}^{2}$ or greater, moderate when iEAO was between $0.85 \mathrm{~cm}^{2} / \mathrm{m}^{2}$ and $0.65 \mathrm{~cm}^{2} / \mathrm{m}^{2}$, and severe when iEAO was $0.65 \mathrm{~cm}^{2} / \mathrm{m}^{2}$ or less.

\section{Angio-Computed Tomography Studies}

An ACT evaluation was planned in patients without a contraindication to administration of contrast material, and 9 of the long-term survivors (32\%) gave consent for such a study; 16 patients refused to undergo the ACT study, and moderate renal failure was considered a contraindication to such an investigation in 3 patients. The result of ACT imaging provided further calculations of the aortic diameters that were compared with those obtained at 2-dimensional echocardiography at last followup. The presence and location of any aortic wall calcification were assessed. ACT studies were carried out on a 64-row computed tomography scanner (LightSpeed VCT; General Electric, Milwaukee, Wis) with the following parameters: retrospective electrocardiographic gating, detector configuration $64 \times 0.625 \mathrm{~mm}$, tube voltage $100 \mathrm{kV}$, tube current 150 to $500 \mathrm{~mA}$ (electrocardiographic-based current modulation with peak current between $70 \%$ and $80 \%$ of the R-R interval), tube rotation time 0.35 seconds, slice thickness $0.625 \mathrm{~mm}$, reconstruction interval $0.625 \mathrm{~mm}$, and standard convolution kernel. Each patient received 60 to $80 \mathrm{~mL}$ of nonionic iodinated contrast medium (iodixanol 320 $\mathrm{mg} / \mathrm{mL}$ : Visipaque 320, GE Healthcare, Oslo, Norway) injected intravenously at a flow rate of 4 to $5 \mathrm{~mL} / \mathrm{s}$, followed by $40 \mathrm{~mL}$ of saline chaser administered at the same flow rate. Scanning was performed in the cranio-caudal direction and spanned the entire thoracic aorta from approximately $2 \mathrm{~cm}$ above the origin of supra-aortic vessels to the lung bases. The start of each computed tomography acquisition was determined by means of bolus tracking at the level of the aortic root using a density threshold of $100 \mathrm{HU}$.

\section{Statistical Analysis}

Data are presented as mean \pm standard deviation and as simple percentages. The linearized rate of postoperative complications was expressed as percent per year (\%/year) \pm standard error. Overall survival was determined by Kaplan-Meier actuarial analysis and expressed as percentage \pm standard error. Student $t$ test or Wilcoxon test for continuous data and chi-square or Fisher test for discrete variables were used, as appropriate. Data analysis was performed by using commercially available SPSS version 17.0 (SPSS, Inc, an IBM Company, Chicago, Ill).

\section{RESULTS \\ Patient Data}

The most significant preoperative patient characteristics are summarized in Table 1 . The mean age was $68 \pm 11$ years (range, 29-84 years), and 85\% (45 patients) were female; mean BSA was $1.68 \pm 0.15 \mathrm{~cm}^{2}$ (range, $1.40-2.10 \mathrm{~cm}^{2}$ ). The predominant valvular lesion was aortic stenosis in 51 patients $(96 \%)$ and aortic regurgitation in 2 patients (4\%); 46 patients $(87 \%)$ were in sinus rhythm, and 7 patients $(13 \%)$ were in chronic atrial fibrillation. Preoperatively, 10 patients $(19 \%)$ were in functional class IV according to the New York Heart Association (NYHA), 32 patients $(60 \%)$ were in class III, and $11(21 \%)$ patients were in class II. The mean NYHA class was $3.0 \pm 0.7$. Cardiovascular risk factors, mainly hypertension and diabetes, were present in 46 patients $(87 \%)$; 1 patient $(2 \%)$ was on chronic hemodialysis. Associated cardiac pathologies were observed in 19 patients, primarily coronary artery disease ( 9 patients, 47\%) and mitral valve disease (7 patients, 37\%). The mean logistic European System for Cardiac Operative Risk Evaluation was $11.2 \pm 13.2$. 
TABLE 1. Summary of patient characteristics

\begin{tabular}{|c|c|}
\hline \multicolumn{2}{|l|}{ Gender } \\
\hline Male & $8(15 \%)$ \\
\hline Female & $45(85 \%)$ \\
\hline \multicolumn{2}{|l|}{ Age (y) } \\
\hline Mean $( \pm \mathrm{SD})$ & $68 \pm 11$ \\
\hline Range & $29-84$ \\
\hline$>80$ & $6(11 \%)$ \\
\hline \multicolumn{2}{|l|}{$\mathrm{BSA}\left(\mathrm{cm}^{2}\right)$} \\
\hline Mean $( \pm \mathrm{SD})$ & $1.68 \pm 0.15$ \\
\hline \multicolumn{2}{|l|}{ Rhythm } \\
\hline Sinus & $46(87 \%)$ \\
\hline $\mathrm{AF}$ & $7(13 \%)$ \\
\hline \multicolumn{2}{|l|}{ NYHA class } \\
\hline I & 0 \\
\hline II & $11(21 \%)$ \\
\hline III & $32(60 \%)$ \\
\hline IV & $10(19 \%)$ \\
\hline \multicolumn{2}{|l|}{ Valvular lesion } \\
\hline Pure or prevalent stenosis & $51(96 \%)$ \\
\hline Pure or prevalent incompetence & $2(4 \%)$ \\
\hline \multicolumn{2}{|l|}{ Cause } \\
\hline Calcific degeneration & $35(66 \%)$ \\
\hline Rheumatic & $15(28 \%)$ \\
\hline Prosthesis failure & $3(6 \%)$ \\
\hline \multicolumn{2}{|l|}{ Log euroSCORE } \\
\hline Mean $( \pm \mathrm{SD})$ & $11.2 \pm 13.2$ \\
\hline
\end{tabular}

$S D$, Standard deviation; $B S A$, body surface area; $N Y H A$, New York Heart Association; euroSCORE, European System for Cardiac Operative Risk Evaluation; $A F$, atrial fibrillation.

\section{Operative Data}

Operative data are summarized in Table 2. AVR was performed on an emergency basis in 3 patients $(6 \%)$, and 6 patients $(11 \%)$ underwent reoperation for dysfunction of a previously implanted aortic $(\mathrm{n}=3)$ or mitral $(\mathrm{n}=3)$ prosthesis; previously implanted aortic prostheses were $19 \mathrm{~mm}$ in 2 patients and $21 \mathrm{~mm}$ in 1 patient. Associated procedures were performed in 20 patients ( $38 \%)$ and were mainly coronary artery bypass grafting ( 9 patients) and mitral valve replacement or repair (7 patients). LV septal myectomy was never performed. Mean aortic crossclamp time was $93 \pm 27$ minutes (range, 50-201 minutes), and mean duration of cardiopulmonary bypass was $122 \pm 43$ minutes (range, 71-323 minutes). A mechanical prosthesis was implanted in 31 patients $(58 \%)$, and a bioprosthesis was implanted in 22 patients $(42 \%)$. Prosthetic sizes were 19 $\mathrm{mm}$ in 3 patients $(6 \%), 21 \mathrm{~mm}$ in 36 patients $(68 \%)$, and $23 \mathrm{~mm}$ in 14 patients $(26 \%)$.

\section{Early Mortality and Morbidity}

There was 1 operative death $(2 \%)$ due to cardiac failure 10 days after combined AVR and mitral valve replacement. In this patient, a 19-mm mechanical prosthesis was inserted in the aortic position with residual mild PPM. Intensive care unit stay more than 72 hours was required in 10 patients $(19 \%)$, and prolonged mechanical ventilation ( $>96$ hours)
TABLE 2. Operative data

\begin{tabular}{lc}
\hline Emergency & $3(6 \%)$ \\
Redo & $6(11 \%)$ \\
CPB time (min) & $122 \pm 43$ \\
$\quad$ Mean \pm SD & \\
ACC time (min) & $93 \pm 27$ \\
$\quad$ Mean \pm SD & \\
Prosthesis size & $3(6 \%)$ \\
$19 \mathrm{~mm}$ & $36(68 \%)$ \\
$21 \mathrm{~mm}$ & $14(26 \%)$ \\
$23 \mathrm{~mm}$ & \\
Prosthesis & $31(58 \%)$ \\
$\quad$ Mechanical & $22(42 \%)$ \\
Biological & \\
Associated procedures & $9(17 \%)$ \\
$\quad$ CABG & $7(13 \%)$ \\
$\quad$ MV surgery & $4(8 \%)$ \\
$\quad$ Other & $1(2 \%)$ \\
Operative mortality & \\
\hline$C P B$, Cardiopulmonary bypass; $S D$, standard deviation; $A C C$, aortic crossclamp; \\
$C A B G$, coronary artery bypass grafting; $M V$, mitral valve.
\end{tabular}

was required in 5 patients $(9 \%)$. Major postoperative complications included transient atrial fibrillation in 20 patients $(38 \%)$, renal insufficiency in 3 patients $(6 \%)$, and atrioventricular block in 3 patients $(6 \%)$. Mean drainage from the chest tubes was $621 \pm 357 \mathrm{~mL}$. Chest reexploration for bleeding was required in 8 patients, but the cause of bleeding was not at the aortotomy site in any of these patients. Patients were discharged 4 to 34 days after AVR (mean, $9.5 \pm 6.0$ days).

\section{Late Survival and Complications}

There were 20 late deaths $(40 \%)$. Causes of late deaths were old age in 5 patients $(25 \%)$, all of whom were aged more than 90 years at the time of death, neoplasms in 4 patients $(20 \%)$, pulmonary embolism in 3 patients $(15 \%)$, cardiac failure in 2 patients $(10 \%)$, stroke in 2 patients $(10 \%)$, renal failure in 1 patient $(5 \%)$, hepatic failure in 1 patient $(5 \%)$, and unknown in 2 patients $(10 \%)$. Actuarial survival is $68 \% \pm 7 \%$ at 10 years and $37 \% \pm 9 \%$ at 15 and 18 years (Figure 1). At last follow-up, 17 patients $(60 \%)$ are in NYHA class I and 11 patients $(40 \%)$ are in class II with a mean NYHA class of $1.43 \pm 0.5(P<.05)$.

Thromboembolic complications occurred in 2 patients 8 and 14 years after AVR with a mechanical prosthesis; both sustained a fatal stroke. Linearized incidence of thromboembolic complications is $0.42 \% \pm 0.30 \%$ patient-years. Endocarditis was observed 2 years after AVR in 1 patient who died at reoperation with a linearized incidence of $0.21 \% \pm 0.21 \%$ patient-years. Another patient underwent successful reoperation after 8 years for dysfunction of a mitral prosthesis implanted at the time of AVR. Linearized incidence of reoperation ( 2 patients) is $0.42 \% \pm 0.30 \%$ patient-years. 


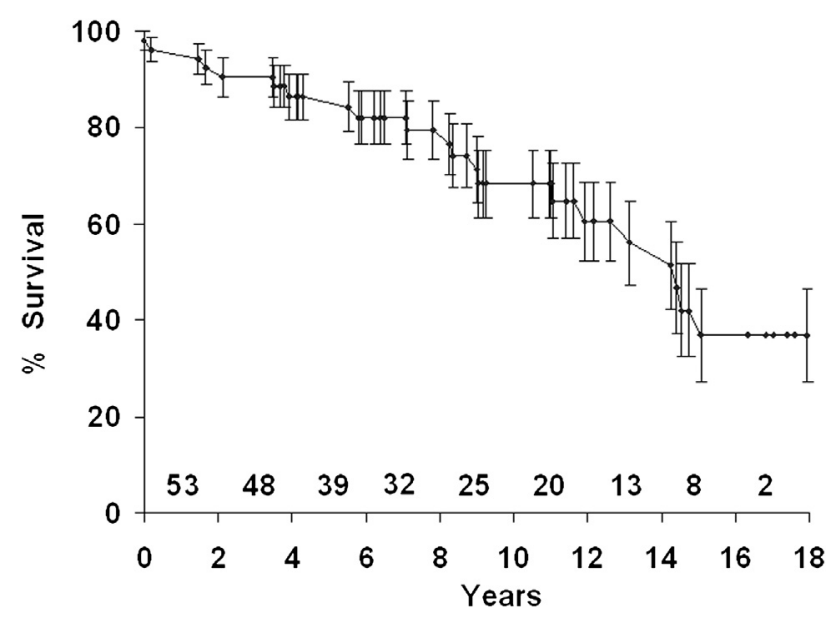

FIGURE 1. Actuarial survival after aortic valve replacement with enlargement of the aortic annulus. Numbers on the horizontal axis indicate patients at risk.

\section{Echocardiographic Data}

Preoperative 2-dimensional echocardiography showed a mean LV ejection fraction of $55 \% \pm 7 \%$. The mean thickness of the LV septum was $12.3 \pm 1.4 \mathrm{~mm}$. The peak and mean transvalvular gradients were $91 \pm 20 \mathrm{~mm} \mathrm{Hg}$ and $56 \pm 11 \mathrm{~mm} \mathrm{Hg}$, respectively. The mean aortic annulus diameter was $19.4 \pm 1.0 \mathrm{~mm}$. The mean aortic root diameter, at the level of the sinuses of Valsalva, was $27.6 \pm 2.5 \mathrm{~mm}$. The mean ascending aorta diameter, at the level of the STJ, was $30.7 \pm 5.0 \mathrm{~mm}$. Other preoperative echocardiographic parameters are shown in Table 3.

At discharge, mean LV ejection fraction was $52 \% \pm 4 \%$, LV septum thickness was $12.1 \pm 0.8 \mathrm{~mm}$, peak transprosthetic gradient was $25 \pm 10 \mathrm{~mm} \mathrm{Hg}$, mean transprosthetic gradient was $15 \pm 6 \mathrm{~mm} \mathrm{Hg}$, and iEOA was $0.91 \pm 0.23$ $\mathrm{cm}^{2} / \mathrm{m}^{2}$. The mean aortic root diameter was $29.9 \pm 2.7$ $\mathrm{mm}$, and the mean diameter at the STJ was $31.2 \pm 6.1 \mathrm{~mm}$.

At latest follow-up, LV ejection fraction was $54 \% \pm 5 \%$, LV septum thickness was $10.8 \pm 1.2 \mathrm{~mm}$, peak transprosthetic gradient was $24 \pm 10 \mathrm{~mm} \mathrm{Hg}$, mean transprosthetic gradient was $14 \pm 6 \mathrm{~mm} \mathrm{Hg}$, and iEOA was $0.88 \pm 0.20$ $\mathrm{cm}^{2} / \mathrm{m}^{2}$. The mean aortic root diameter was $31.1 \pm 3.7$ $\mathrm{mm}$, and the mean diameter at the STJ was $31.2 \pm 5.3$ $\mathrm{mm}$. For valve sizes in patients with $19-\mathrm{mm}$ prostheses, the peak transprosthetic gradient was $18 \pm 10 \mathrm{~mm} \mathrm{Hg}$, mean transprosthetic gradient was $11 \pm 6 \mathrm{~mm} \mathrm{Hg}$, and iEOA was $0.77 \pm 0.18 \mathrm{~cm}^{2} / \mathrm{m}^{2}$. In patients with a $21-\mathrm{mm}$ prosthesis, the peak transprosthetic gradient was $26 \pm 10$ $\mathrm{mm} \mathrm{Hg}$, mean transprosthetic gradient was $15 \pm 7 \mathrm{~mm}$ $\mathrm{Hg}$, and iEOA was $0.91 \pm 0.21 \mathrm{~cm}^{2} / \mathrm{m}^{2}$. In patients with a $23-\mathrm{mm}$ prosthesis, peak transprosthetic gradient was $18 \pm 4 \mathrm{~mm} \mathrm{Hg}$, mean transprosthetic gradient was $11 \pm 2$ $\mathrm{mm} \mathrm{Hg}$, and iEOA was $1.02 \pm 0.34 \mathrm{~cm}^{2} / \mathrm{m}^{2}$.

A significant difference was found between the LV wall thickness and the aortic root diameter at follow-up when compared with preoperative and discharge values $(P<.05$ and $P<.001$, respectively) and between transprosthetic gradients at discharge and follow-up when compared with preoperative values $(P<.001)$. Finally, no cases of periprosthetic leak were observed, but 3 patients had mild mitral insufficiency.

\section{Angio-Computed Tomography Data}

An ACT study was performed in 9 patients at latest follow-up. Patient age ranged from 35 to 86 years at the time of the study (mean, $67 \pm 15$ years); ACT was performed 3 to 17 years from AVR (mean, $10.7 \pm 5.0$ years). Mean aortic root diameter was $29.7 \pm 5.8 \mathrm{~mm}$, and mean diameter at the STJ was $29.0 \pm 6.5 \mathrm{~mm}$, with no significant difference with corresponding diameters at echocardiography $(P=$ not significant). Diffuse calcifications of the aorta were observed in 2 patients (aged 84 and 86 years). Calcific spots mainly on the ascending aorta and arch were present in 6 patients, but no calcifications were seen in 1 patient (aged 35 years). Calcifications corresponding to the site of the pericardial patch were identified in 4 patients (Figure 2).

\section{Evaluation of Patient-Prosthesis Mismatch}

According to intraoperative measurements, the aortic annulus size ranged from 17 to $21 \mathrm{~mm}$ (mean, $18.7 \pm 0.6$ ). The mean size of implanted prostheses was $21.4 \pm 1.0$ $\mathrm{mm}$, yielding a size gain of $1.36 \pm 0.5 \mathrm{~mm}$. A prosthesis 1 size larger was implanted in 17 patients and 2 sizes larger was implanted in 19 patients. Moderate PPM was observed in 2 patients, with a $19-\mathrm{mm}$ mechanical prosthesis. In all other patients, the iEOA was more than $0.85 \mathrm{~cm}^{2} / \mathrm{m}^{2}$ (mean iEOA, $0.91 \pm 0.2 \mathrm{~cm}^{2} / \mathrm{m}^{2}$ at discharge and $0.88 \pm 0.2 \mathrm{~cm}^{2} /$ $\mathrm{m}^{2}$ at follow-up) (Table 3). Had the prosthetic size been selected simply on the basis of intraoperative measurements, by implanting the prosthesis that would have fitted the measured annulus, this would have caused moderate PPM in all patients. The iEOA of the implanted prostheses would have been $0.74 \pm 1.4 \mathrm{~cm}^{2} / \mathrm{m}^{2}$, which is significantly different from that actually obtained $\left(0.91 \pm 0.2 \mathrm{~cm}^{2} / \mathrm{m}^{2}\right)$ after EAA.

\section{DISCUSSION}

In patients with calcific aortic stenosis, the main goals of AVR are relief from LV obstruction and avoidance of PPM by implanting a prosthesis of adequate size. Although the concept of PPM introduced by Rahimtoola ${ }^{1}$ more than 40 years ago is currently well recognized, the impact of PPM on late survival after AVR is still controversial. Nevertheless, although satisfactory hemodynamic results have been reported with small-sized prosthetic valves, ${ }^{11,12}$ there is sufficient evidence that PPM is associated with increased mortality, decreased exercise tolerance, and reduced LV mass regression after AVR for aortic stenosis. ${ }^{13-16}$ Furthermore, it has been also shown that recipients of a 19-mm St Jude Medical Inc (St Paul, Minn) aortic 
TABLE 3. Echocardiographic data

\begin{tabular}{lcccc}
\hline \multicolumn{1}{c}{ Values } & Preoperative & Discharge & Follow-up & $\begin{array}{c}\boldsymbol{P} \\
\text { value }\end{array}$ \\
\hline EF $(\%)$ & $55 \pm 7$ & $52 \pm 4$ & $54 \pm 5$ & NS$^{*}$ \\
& & & & \\
EDV (mL) & $85 \pm 35$ & $81 \pm 13$ & $80 \pm 25$ & $\mathrm{NS}^{*}$ \\
EDD (mm) & $47 \pm 6$ & $\mathrm{NA}$ & $45 \pm 6$ & $\mathrm{NS}^{*}$ \\
IVS (mm) & $12.3 \pm 1.4$ & $12.1 \pm 0.8$ & $10.8 \pm 1.2$ & $<.05^{*}$ \\
& & & & \\
Aortic annulus (mm) & $19.4 \pm 1.0$ & - & - & \\
Aortic root (mm) & $27.6 \pm 2.5$ & $29.9 \pm 2.7$ & $31.1 \pm 3.7$ & $<.001^{*}$ \\
STJ (mm) & $31.0 \pm 5.0$ & $31.2 \pm 6.1$ & $31.0 \pm 5.3$ & $\mathrm{NS}$ \\
& & & & \\
Vmax (m/s) & $4.6 \pm 0.5$ & $2.4 \pm 0.5$ & $2.4 \pm 0.5$ & $<.001 \dagger$ \\
PG (mm Hg) & $91 \pm 20$ & $25 \pm 10$ & $24 \pm 10$ & $<.001 \dagger$ \\
MG (mm Hg) & $56 \pm 11$ & $15 \pm 6$ & $14 \pm 6$ & $<.001 \dagger$ \\
iEOA & - & $0.91 \pm 0.23$ & $0.88 \pm 0.20$ & $\mathrm{NS} \ddagger$ \\
\hline
\end{tabular}

$E F$, Ejection fraction; $E D V$, end-diastolic volume; $E D D$, end-diastolic diameter; $I V S$, interventricular septum; STJ, sinotubular junction; Vmax, maximum velocity; $P G$, peak gradient; $M G$, mean gradient; $i E O A$, indexed effective orifice area; $N A$, not available; $N S$, not significant. *Follow-up versus preoperative and discharge. $\dagger$ Follow-up and discharge versus preoperative. ††Follow-up versus discharge.

prosthesis have a higher prevalence of important PPM with a higher rate of cardiac events at 15 years when compared with 21 -mm valves. ${ }^{17}$ Another study by our group demonstrated that patients with a 21-mm aortic St Jude prosthesis and BSA of $1.70 \mathrm{~m}^{2}$ or greater showed a significant incidence of PPM detected at cardiopulmonary exercise testing. ${ }^{18} \mathrm{On}$ the basis of these considerations in patients with a diminutive aortic annulus, particularly in those with a large BSA, EAA seems indicated to minimize PPM. Alterative techniques include the use of homografts, autografts, stentless valves, or total aortic root replacement; however, most of these may be time-consuming and cumbersome with intrinsic morbidity, and therefore not too appealing to many surgeons.

The techniques of EAA were pioneered by Nicks and colleagues $^{2}$ in 1970 and subsequently reported by others. ${ }^{3-5}$ A simplified technique was described by Nunez and colleagues ${ }^{8}$ in 1983. EAA is performed as much as in the description by Manouguian and Seybold-Epting ${ }^{5}$ by prolonging the aortotomy to divide the commissure between the left and noncoronary cusps into the anterior mitral leaflet, but without entering the left atrial roof and closing the defect with a Dacron patch. We have adopted this technique, using at variance mostly a patch of bovine pericardium, showing that it is simple and reproducible. ${ }^{6}$ In a second series of 16 patients, there was no operative mortality with stability of aortic diameters at 30 months of follow-up, confirming the safety and effectiveness of this technique in allowing adequate EAA. ${ }^{7}$ Large series of EAA associated with AVR have been reported ${ }^{19-24}$ using a variety of techniques and materials, such as autologous or xenograft pericardium or synthetic patches, but reports on long-term follow-up are limited. Piehler and associates ${ }^{19}$ reported on 96 patients undergoing EAA with the technique by Nicks and colleagues ${ }^{2}$ with autologous pericardium and a maximum follow up of 15 years; 24 patients required reoperation, and in all of them the pericardium was found to be well healed, not dilated but thickened and often calcified. Kulik and colleagues ${ }^{23}$ reported their experience with 114 patients requiring EAA with the techniques by Nicks and colleagues $^{2}$ or Manouguian and Seybold-Epting ${ }^{5}$ using both a patch of synthetic material or autologous pericardium. At 10-year follow-up, they observed an actuarial survival of $69.7 \%$ and $86.4 \%$ of freedom from congestive heart failure, data not significantly different from those having AVR alone during the same period. In all other large series reported long-term follow-up data are not available. ${ }^{20-22,24}$

We are the first to report an extended follow-up (up to 18 years) of patients having AVR and concomitant EAA. Furthermore, we provide long-term data on the variations with time of the aortic root dimensions both at the level of the sinuses of Valsalva and at the STJ assessed by echocardiographic and ACT studies with the aim of verify stability
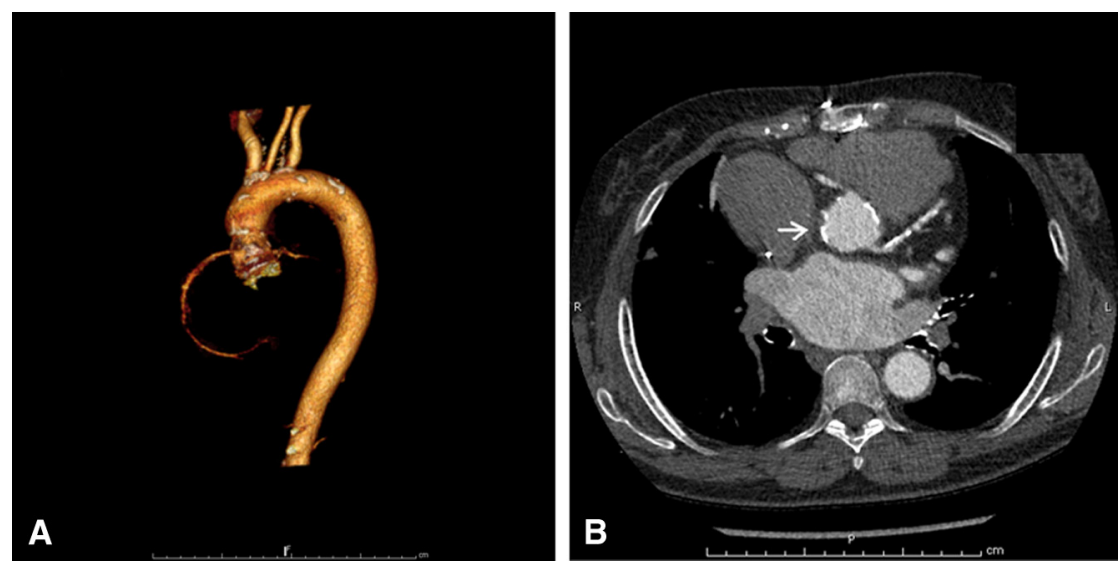

FIGURE 2. A, Angio-computed tomography of a 61-year-old woman 12 years after operation showing normal aortic diameters with calcific spots mainly located in the arch. B, Transverse section showing calcific deposits in the aortic root corresponding to the site of the pericardial patch (arrow). 
of the procedure, an issue seldom addressed in the literature. We have shown that EAA can be performed with low mortality and without significantly increasing operative times as observed by others. ${ }^{21,22,24}$ EAA is an effective procedure because it minimizes the occurrence of PPM. In our series, severe PPM was never observed after EAA, and only 2 patients presented with a moderate PPM. Mild PPM is unavoidable after AVR even when associated with EAA because of the intrinsic gradient of any implanted stented mechanical or biological prosthesis; however, mild PPM did not influence late patient outcome because most of the late deaths were due to noncardiac causes. Further findings of our study indicate that this procedure was not associated with major postoperative complications, in particular, no cases of paravalvular leak or significant mitral regurgitation were observed. Echocardiographic controls demonstrated stability of aortic diameters with time, and such data were confirmed by ACT controls performed in late survivors. No cases of aneurysmal dilatation were observed. Although the patch is inserted in a high-pressure environment, xenograft pericardial tissue does not dilate and is not prone to late aneurysm formation, most likely because of the limited size of the patch or because it may shrink or even calcify with time, ${ }^{25}$ as much as it occurs with autologous pericardium, ${ }^{19}$ thus representing a valid alternative to synthetic material. Calcification of the aorta was observed in our ACT studies, some of them corresponding to the site of the pericardial patch insertion.

\section{Study Limitations}

The major limitation of this study is represented by its retrospective nature, including a limited number of patients albeit with a relatively uncommon procedure and a partially incomplete follow-up; however, accurate evaluation of long-term survivors with echocardiographic and ACT studies provided meaningful data to assess the effectiveness of the procedure up to 18 years of follow-up. Our data demonstrate that the technique we used, proposed by Nunez and colleagues, ${ }^{8}$ is simple, allows a prosthesis 1 to 2 sizes larger to be inserted, does not interfere with the function of the mitral valve, and provides adequate relief of LV obstruction. We also confirm that xenograft pericardium is a versatile material for intracardiac applications, is extremely useful for EAA because it allows adequate hemostatic sutures, is strong enough to hold stitches, and does not tend to dilate with time. As an alternative, autologous pericardium could be used, but we found that bovine pericardium is stiffer but still pliable enough and easy to work with.

\section{CONCLUSIONS}

EAA during AVR is a valid option in patients with a small aortic annulus, and it should be strongly considered to prevent PPM and its deleterious long-term effects; however, considering the rather high mean age of patients in this series, whether these conclusions may be applied to young, active subjects must be verified by further studies.

\section{References}

1. Rahimtoola SH. The problem of valve prosthesis-patient mismatch. Circulation. 1978;58:20-4.

2. Nicks R, Cartmill T, Bernstein L. Hypoplasia of the aortic root. The problem of aortic valve replacement. Thorax. 1970;25:339-46.

3. Blank RH, Pupello DF, Bessone LN, Harrison EE, Sbar S. Method of managing the small aortic annulus during valve replacement. Ann Thorac Surg. 1976;22: 356-61.

4. Rittenhouse EA, Sauvage LR, Stamm SJ, Mansfield PB, Hall DG, Herndon PS. Radical enlargement of the aortic root and outflow tract to allow valve replacement. Ann Thorac Surg. 1979;27:367-73.

5. Manouguian S, Seybold-Epting W. Patch enlargement of the aortic valve ring by extending the aortic incision into the anterior mitral leaflet. New operative technique. J Thorac Cardiovasc Surg. 1979;78:402-12.

6. Bortolotti U, Mossuto E, Maraglino G, Sturaro M, Milano A, Livi U, et al. Annular enlargement during aortic valve replacement: preliminary results with a simplified technique. J Card Surg. 1992;7:235-9.

7. Bortolotti U, Scioti G, Milano A, Nardi C, Tartarini G. Enlargement of the aortic annulus with glutaraldehyde-fixed bovine pericardium during aortic valve replacement. J Heart Valve Dis. 1998;7:299-304.

8. Nunez L, Gil Aguado M, Pinto AG, Larrea JL. Enlargement of the aortic annulus by resecting the commissure between the left and noncoronary cusps. Texas Heart Inst J. 1983;10:301-3.

9. Pibarot P, Dumesnil JG. Hemodynamic and clinical impact of prosthesis-patient mismatch in the aortic valve position and its prevention. J Am Coll Cardiol. 2000; 36:1131-41.

10. Akins CW, Miller DC, Turina MI, Kouchoukos NT, Blackstone EH, Grunkemeier GL, et al. Guidelines for reporting mortality and morbidity after cardiac valve interventions. J Thorac Cardiovasc Surg. 2008;135: 732-8.

11. Okamura H, Yamaguchi A, Tanaka M, Naito K, Kimura N, Kimura C, et al. The $17-\mathrm{mm}$ St. Jude Medical Regent valve is a valid option for patients withy small aortic annulus. Ann Thorac Surg. 2009;87:90-4.

12. Garatti A, Mori F, Innocente F, Canziani A, Gagliardotto P, Mossuto E, et al. Aortic valve replacement with $17-\mathrm{mm}$ mechanical prostheses: is patient-prosthesis mismatch a relevant phenomenon? Ann Thorac Surg. 2011;91:71-8.

13. Del Rizzo DF, Abdoh A, Cartier P, Doty D, Westaby S. Factors affecting left ventricular mass regression after aortic valve replacement with stentless valves. Semin Thorac Cardiovasc Surg. 1999;11:114-20.

14. Tasca G, Brunelli F, Cirillo M, Dalla Tomba M, Mhagna Z, Troise G, et al. Impact of valve prosthesis-patient mismatch on left ventricular mass regression following aortic valve replacement. Ann Thorac Surg. 2005;79:505-10.

15. Mohty-Echahidi D, Matloff JF, Giraud SE, Schaff HV, Grill DE, EnriquezSarano ME, et al. Impact of prosthesis-patient mismatch on long-term survival in patients with small St. Jude Medical mechanical prostheses in the aortic position. Circulation. 2006;113:420-6.

16. Blais C, Dumesnil JC, Baillot R, Simard S, Doyle D, Pibarot P. Impact of valve prosthesis-patient mismatch on short-term mortality after aortic valve replacement. Circulation. 2006;113:570-6.

17. Milano AD, De Carlo M, Mecozzi G, D'Alfonso A, Scioti G, Nardi C, et al. Clinical outcome in patients with 19-mm and 21-mm St. Jude aortic prostheses: comparison at long-term follow-up. Ann Thorac Surg. 2002;73:37-43.

18. De Carlo M, Milano A, Musumeci G, Tartarini G, Biadi O, Benedetti M, et al. Cardiopulmonary exercise testing in patients with $21 \mathrm{~mm}$ St. Jude Medical aortic prosthesis. J Heart Valve Dis. 1999;8:522-9.

19. Piehler JM, Danielson GK, Pluth JR, Orszulak TA, Puga FJ, Schaff HV, et al. Enlargement of the aortic root or annulus with autogenous pericardial patch during aortic valve replacement. Long-term follow-up. J Thorac Cardiovasc Surg. 1983; 86:350-8.

20. Castro LJ, Arcidi JM Jr, Fisher AL, Gaudiani VA. Routine enlargement of the small aortic root: a preventive strategy to minimize mismatch. Ann Thorac Surg. 2002;74:31-6.

21. Dhareshwar J, Sundt TM III, Dearani JA, Schaff HV, Cook DJ, Orszulak TA. Aortic root enlargement: what are the operative risks. J Thorac Cardiovasc Surg. 2007;134:916-24. 
22. Peterson MD, Borger MA, Feindel CM, David TE. Aortic annular enlargement during aortic valve replacement: improving results with time. Ann Thorac Surg. 2007;83:2044-9.

23. Kulik A, Al-Saigh M, Chan V, Masters RG, Bedard P, Lam BK, et al. Enlargement of the small aortic root during aortic valve replacement: is there a benefit? Ann Thorac Surg. 2008;85:94-101.
24. Coutinho GF, Correia PM, Pauperio G, de Oliveira F, Antunes MJ. Aortic roo enlargement does not increase the surgical risk and short-term patient outcome. Eur J Cardiothorac Surg. 2011;40:441-7.

25. Gabbay S, Bortolotti U, Factor S, Shore DF, Frater RWM. Calcification of implanted xenograft pericardium. Influence of site and function. J Thorac Cardiovasc Surg. 1984;87:782-7. 